\title{
What type of weight loss program do postpartum women want? Treatment preferences of postpartum women in two community settings
}

\author{
Suzanne Phelan ${ }^{1}$, Katelyn Smith ${ }^{1}$, John-Mark Steele ${ }^{1}$, Dawn Wilt ${ }^{2}$, Sally Ames $^{3}$, Linda McClure ${ }^{2}$ \\ ${ }^{1}$ California Polytechnic State University \\ ${ }^{2}$ Women, Infant, Children's Nutritional Program \\ ${ }^{3}$ San Luis Coastal Unified School District
}

\begin{abstract}
Approximately $25 \%$ of women experience major weight gain after pregnancy, retaining more than $4.5 \mathrm{~kg}$. Preliminary efforts to promote postpartum weight loss have encountered some success, but little is known about the types of programs of greatest interest to postpartum women. The purpose of this study was to better understand the weight control needs and preferences of postpartum women in the Women, Infants and Children (WIC) Nutrition program $(\mathrm{N}=100)$ and an Adult Education Parenting (AEP) program $(\mathrm{N}=$ 75). A self-report questionnaire was used to collect participants' demographic and weight history information as well as participants' degree of interest in various weight loss treatment modalities. Results indicated that, independent of weeks postpartum and breastfeeding status, women in both groups (WIC and AEO) experienced high postpartum weight retention, and greater weight retention was reported in WIC than AEP $(7.6 \pm 7.7 \mathrm{~kg}$ vs. $3.2 \pm 6.9 \mathrm{~kg}$, respectively; $\mathrm{p}=.0001)$. When asked about types of weight control treatments, women in both setting expressed greatest interest in weekly face-to-face group meetings, but $66.2 \%$ of AEP and $60.6 \%$ of WIC reported needing childcare to attend such meetings. Women in both settings reported interest in an Internet-based program, particularly one that integrated monthly face-to-face meetings. Future randomized controlled trials are needed to examine the efficacy of Internet-based treatment in reducing postpartum weight retention in diverse patient populations.
\end{abstract}

(c) 2008 Californian Journal of Health Promotion. All rights reserved.

Keywords: Obesity, WIC program, postpartum weight retention, internet-based treatment.

\section{Introduction}

Each year, approximately four million American women give birth. Of these women, an estimated $25 \%$ experience major weight retention after pregnancy, retaining more than $4.5 \mathrm{~kg}(10 \mathrm{lb})$ at 1 year postpartum (Keppel \& Taffel, 1993; Ohlin \& Rossner, 1990). High postpartum weight retention has troubling long-term consequences for the health of the mother, including a continued trajectory of weight gain over time (Linne, Dye, Barkeling, \& Rossner, 2004; Rooney \& Schauberger, 2002) and increased risk of lifetime obesity, cardiovascular disease, and type 2 diabetes. Moreover, women with high postpartum weight retention are heavier prior to their next pregnancy, which increases their risk of pregnancy-related complications, obesity, and serious health complications in the offspring (Boney, Verma, Tucker, \& Vohr, 2005; Driul et al., 2008; Olson, Strawderman, \& Dennison, 2008; SamuelsKalow et al., 2007; Villamor \& Cnattingius, 2006; Watkins \& Botto, 2001).

Paralleling obesity trends, high postpartum weight retention is particularly problematic for women of ethnic minority and lowsocioeconomic status (Kac, Benicio, VelasquezMelendez, \& Valente, 2004; Parker \& Abrams, 1993; Walker, Timmerman, Sterling, Kim, \& Dickson, 2004). Low-income Hispanic women, in particular, lose less weight during the initial 3-6 month postpartum period (Walker, Sterling, \& Timmerman, 2005). Moreover, weight trends indicate that between 3 and 12 months 
postpartum, while Caucasian women continue to lose weight, Hispanic women experience weight gains (L. Walker et al., 2004; Walker, 2007).

Women who are overweight or obese prior to pregnancy are also at higher risk of postpartum weight retention (McKeown \& Record, 1957; Institute of Medicine, 1990). This may be due to diminished rate of weight loss during later postpartum period (Gunderson, Abrams, \& Selvin, 2001). The studies showing the effects of breastfeeding on postpartum weight retention have been mixed and likely influenced by both the duration and intensity of breastfeeding (Baker et al., 2008; Gore, Brown, \& West, 2003). Of note, gestational weight gain is the strongest and most consistent predictor of postpartum weight retention (Gore et al., 2003; Greene, Smiciklas-Wright, Scholl, \& Karp, 1988). Thus, one approach to preventing postpartum weight retention has been to prevent excessive weight gain during pregnancy(Artal, Catanzaro, Gavard, Mostello, \& Friganza, 2007; Kinnunen et al., 2007; Olson, Strawderman, \& Reed, 2004; Polley, Wing, Meier, Sims, \& DeBranski, 1997). While a promising strategy, limiting weight gain during pregnancy is complicated by concerns about the safety of the mother and developing fetus. Thus, a major advantage of intervening during the postpartum period is that more intensive weight control strategies can be used without the risk of negatively affecting birth outcomes.

Preliminary diet and exercise interventions to promote postpartum weight loss have met with some success (Leermakers, Anglin, \& Wing, 1998; Lovelady, Garner, Moreno, \& Williams, 2000). However, postpartum interventions have been limited by high attrition ranging from 31 to $42 \%$. During the postpartum period, women are busy with infant care and experiencing physical, social, and emotional adjustments to motherhood that may hamper adherence to standard interventions. More information is needed about the types of programs of greatest interest to postpartum women. As attitudes toward managing weight may differ among different race/ethnic and income categories (Groth \& David, 2008), research is also needed to better understand postpartum weight management preferences across different demographic populations.

Two settings commonly proposed as targets for postpartum interventions are the Women, Infants and Children (WIC) Nutrition program, servicing low income postpartum women, and fee-for-service Adult Education Parenting (AEP) classes for postpartum women (National Heart, Lung and Blood Institute, 2008). WIC has been in place for over two decades and serves eight million low-income postpartum women and their families each month nationwide (Department of Agriculture, 2008). Almost half of US pregnant women and/or their children enroll in WIC at some point during the postpartum year (Cole, 2001). The purpose of the program is to improve the nutritional status and health of low-income, nutritionally at risk pregnant or lactating women and children below the age of five by providing supplementary food (in the form of coupons or checks redeemable for specific food items), nutrition education, and referrals to other medical and social services. California is the second largest WIC program in the nation, serving about 1.4 million participants monthly (Association, 2008). AEP classes are available in every metropolitan city and local communities throughout the United States. These programs are consumer-oriented (Bradley, 1995), overseen by a variety of establishments (medical, educational, social services), and generally provide parents with information about child development, safety, nutrition, sleep habits, and discipline. In contrast to WIC, data from most parenting classes suggest low attendance for racial- and ethnic-minorities from low-income backgrounds (Caspe \& Lopez, 2006; Chow, Jaffee, \& Snowden, 2003).

While both settings service postpartum mothers, little is known about the weight control needs and preferences of postpartum women in these settings. Therefore, the purpose of this study was to 1) compare patient characteristics and magnitude of postpartum weight retention in WIC and AEP settings; 2) examine the extent to which women in these settings desire to lose weight; and, 3) determine women's treatment preferences for weight loss programs. Findings from this research are important for developing 
Phelan, S., Smith, K., Steele, J.M., Wilt, D., Ames, S., and McClure, L. / Californian Journal of Health Promotion 2010, Volume 8 ,

Issue 1, 22 - 31

future targeted postpartum weight-loss interventions.

\section{Methods}

\section{Participants}

Women were approached at the time of their regularly scheduled Women, Infants, and Children (WIC) postpartum visit or at the weekly adult education parenting (AEP) class between April and June of 2008. The study included adult $(>18)$ women who were six weeks postpartum at these settings with no other exclusionary criteria. Approximately seventy percent of participants approached agreed to participate in the study, leaving a final sample size of 100 WIC and 75 AEP participants. Informed consent in both English and Spanish was obtained, and the study was approved by the California Polytechnic Institutional Review Board, San Luis Obispo, CA.

\section{Questionnaire}

The questionnaire was developed to assess the weight control treatment preferences of postpartum women in San Luis Obispo WIC and AEP classes. Questions were developed in English and Spanish, but back-translating was not conducted. The questions were reviewed for literacy, and revised for content based on consultations with obesity researchers, WIC dietitians, WIC paraprofessionals, coordinators and teachers of the AEP program, and in five patients, selected at random, from each program. The final questionnaire gathered self-reported demographic information (current weight, height, week's gestation, parity, language, employment, breastfeeding status). Self-reported weight and height were converted into BMI (weight in kilograms divided by height in meters squared) and categorized as normal weight (BMI between 18.5 and 24.9) and overweight (BMI > 25). The survey also assessed participants' overall interest in a postpartum weight loss program and degree of interest in various weight loss treatment modalities, including weekly groups at their healthcare setting, internet-based program, internet-based program with monthly group meetings, monthly home visits (targeting patient or patient and her family), weekly mailings, weekly telephone calls, and weekly text-messaging. Degree of interest was indicated on a seven point Likert scale, where $1=$ not at all interested, 4= somewhat interested, and $7=$ extremely interested. Anchors were not provided for the other numbers $(2,3,5$, and 6). Questions also assessed use of the Internet and Internetavailability from home. One question asked about ability to attend face-to-face meetings if childcare was not provided. The questionnaire took approximately ten minutes to complete, and compensation was not provided.

\section{Statistics}

The data collected from the questionnaires was coded and analyzed using Statistical Package for Social Sciences (SPSS 9.0). Both t-tests and Chi-square tests were used in the analysis. The independent t-test was used to compare groups (i.e., WIC vs. AEP; Breastfeeders vs. nonbreastfeeders, Spanish vs. English speakers, early ( $<12$ months) vs. late ( $>12$ months) postpartum) on continuous measures, including pre and post pregnancy body mass index (BMI), parity, and degree of interest in the different programs. The Chi-square test was used to compare groups on categorical measures, including body mass index (BMI), language, use of the Internet and email. Linear regression analyses, adjusting for weeks postpartum and breastfeeding status, were also conducted to examine the relationship between postpartum setting (WIC or AEP) and postpartum weight retention, pre-to post-pregnancy changes in BMI and weight. Linear regression analyses were also conducted to examine variables related to degree of interest in postpartum weight loss. The sample size of this study (100 WIC and 75 AEP) was calculated to provide at least $80 \%$ power for detecting effect sizes ranging from 0.28 to 0.37 for continuous outcomes, with a $5 \%$ type I error rate.

\section{Results}

As expected, many of the demographic characteristics between WIC and AEP were statistically different (Table 1). Women in WIC were younger, heavier, and had slightly more children, on average. While $56 \%$ of women in the WIC group were Spanish-speaking, 92\% of women in the AEP group were English- 
speaking. Importantly, while most participants in the WIC setting were seen early during the postpartum period (i.e., within six months postpartum), most at the AEP setting were seen at two years postpartum. The majority in both groups reported having a home computer with Internet access at home, but percentages were significantly lower in WIC than AEP (Table 1). Although English-speakers were more likely to have a computer than Spanish speakers $(94.5 \%$ vs. $31.0 \% ; \mathrm{p}=.0001)$, nearly $40 \%$ of monolingual Spanish speakers reported having a computer at home. Among those having Internet access (at work or home), $80.0 \%$ of WIC and $97.0 \%$ of AEP reported using the Internet at least once each week, and mostly (56\% and $95 \%$, respectively) from home.

\section{Magnitude of postpartum weight retention} Both groups experienced high postpartum weight retention, but greater weight retention was reported in WIC than AEP $(\mathrm{p}=.0001$;

Table 1

Characteristics of postpartum women in WIC or a community-based adult education program (AEP) for postpartum moms.

\begin{tabular}{|c|c|c|c|c|}
\hline & $\begin{array}{l}\text { Overall } \\
N=175 \\
\end{array}$ & $\begin{array}{c}\text { WIC } \\
\mathbf{N}=100\end{array}$ & $\begin{array}{c}\text { AEP } \\
N=75\end{array}$ & p-value \\
\hline Age & $29.7 \pm 7.2$ & $25.6 \pm 5.8$ & $35.5 \pm 4.5$ & .0001 \\
\hline Spanish Speaking (\%) & 35.4 & 56.0 & 2.7 & .0001 \\
\hline Pre-pregnancy BMI, $\mathrm{M} \pm \mathrm{SD}$ & $24.7 \pm 5.4$ & $26.3 \pm 5.8$ & $22.5 \pm 3.8$ & .0001 \\
\hline Postpartum BMI, $\mathrm{M} \pm \mathrm{SD}$ & $26.9 \pm 6.4$ & $29.3 \pm 6.8$ & $23.7 \pm 4.1$ & .0001 \\
\hline Overweight/obese pre-pregnancy (\%) & 42.2 & 57.6 & 21.6 & .0001 \\
\hline Overweight/obese postpartum (\%) & 62.8 & 79.8 & 39.7 & .0001 \\
\hline High postpartum weight retention (> $5 \mathrm{~kg}),(\%)$ & 56.3 & 58.2 & 30.6 & .0001 \\
\hline Months postpartum, $\mathrm{M} \pm \mathrm{SD}$ & $15.4 \pm 6.0$ & $7.2 \pm 10.6$ & $26.3 \pm 15.6$ & .0001 \\
\hline$<6 \mathrm{mo}(\%)$ & 37.2 & 55.1 & 13.5 & \multirow{3}{*}{0001} \\
\hline $6-12 \mathrm{mo}(\%)$ & 25.0 & 40.8 & 4.10 & \\
\hline$>12 \mathrm{mo}(\%)$ & 37.8 & 4.10 & 82.4 & \\
\hline Number of Children, $\mathrm{M} \pm \mathrm{SD}$ & $1.8 \pm 0.9$ & $1.9 \pm 1.1$ & $1.6 \pm 0.6$ & .01 \\
\hline Currently working for pay (\%) & 39.1 & 38.0 & 40.6 & .735 \\
\hline Have home computer with internet access (\%) & 69.6 & 56.0 & 95.8 & .0001 \\
\hline Have email address $(\%)$ & 68.0 & 48.0 & 97.1 & .0001 \\
\hline Use internet weekly $(\%)$ & 89.7 & 48.0 & 91.5 & .0001 \\
\hline Use text messaging weekly (\%) & 49.4 & 51.0 & 47.1 & .616 \\
\hline Currently breastfeeding (\%) & 69.6 & 51.0 & 33.8 & .030 \\
\hline
\end{tabular}

$\mathrm{M}=$ mean; $\mathrm{SD}=$ standard deviation. WIC $=$ Women, Infant, and Children's nutritional program.

$\mathrm{AEP}=$ Adult Education Program. $\mathrm{BMI}=$ Body mass index

Table 1), even after adjusting for breastfeeding status and weeks postpartum $(\mathrm{p}=.001)$. Similarly, in adjusted analyses, WIC women had significantly greater increases from prepregnancy to postpartum in BMI $(\mathrm{p}=.001)$, and weight $(\mathrm{p}=.001)$ compared with AEP women.

\section{Prevalence and characteristics of women desiring postpartum weight loss in two settings}

The majority of participants in both settings expressed interest in participating in a postpartum weight loss program, but a greater 
percentage of WIC than AEP reported such an interest ( $84 \%$ vs. $57 \%$, respectively; $\mathrm{p}=.0001$ ). Women with high postpartum weight retention $(>5 \mathrm{~kg})$ in both WIC (5.9 1.5 vs. $4.22 .5 ; \mathrm{p}=$ $.0001)$ and AEP (5.2 2.0 vs. $3.11 .7 \mathrm{p}=.01$ ) were more likely to report an interest in postpartum weight loss than women with less postpartum weight retention $(<5 \mathrm{~kg})$. Women who were overweight/obese before pregnancy were also more likely to report being interested in postpartum weight loss compared with women who were normal weight before pregnancy in AEP $(5.0 \pm 2.1$ vs. $3.0 \pm 1.6 \mathrm{p}=$ $.0001)$ but the effect was less apparent in WIC $(5.5 \pm 2.0$ vs $4.9 \pm 2.2 ; p=.17)$. Surprisingly, in both settings, level of interest in postpartum weight loss did not vary based on breastfeeding status (ps > .52) or number of weeks postpartum (ps > .65). Although AEP had very few Spanish speakers, in WIC, no significant differences in magnitude of interest was seen between Spanish and English speakers $(5.3 \pm 1.9$ vs $5.2 \pm 2.3 p=$ .43). In multiple linear regression analysis, magnitude of postpartum weight retention (Beta $=.31 ; \mathrm{t}=4.1 ; \mathrm{p}=.0001)$ and pre-pregnancy obesity (Beta=.18; $\mathrm{t}=2.2 ; \mathrm{p}=.02$ ) were the strongest predictors of degree of interest in postpartum weight loss, independent of setting $(\mathrm{p}=.15)$, weeks postpartum $(\mathrm{p}=.54)$, breastfeeding status $(\mathrm{p}=.58)$, language of origin $(\mathrm{p}=.60)$, and age $(\mathrm{p}=.90)$ which were not significant predictors.

\section{Treatment preferences for different types of weight loss programs}

Among women reporting an interest in postpartum weight loss, weekly face-to-face group meetings was the most preferred modality in both settings, but the majority of women in both WIC (60.6\%) and AEP (66.2\%) reported needing childcare to attend such meetings. Despite differences in computer access (Table 1 ), women in both settings showed a similar amount of interest in an Internet-based program (Table 2), and, in particular, an interest in an Internet-based program that included monthly face-to-face meetings. Although women in both settings were at least "somewhat interested" in most modalities, WIC women reported stronger preferences than AEP women for programs that involved weekly mailings, telephone calls, textmessaging, or monthly home visits - both with and without family involvement.

Table 2.

Interest in different types of postpartum weight loss programs among women in WIC or a community-based adult education program (AEP).

\begin{tabular}{|c|c|c|c|c|}
\hline & $\begin{array}{l}\text { Overall } \\
\mathbf{N}=127 \\
\end{array}$ & $\begin{array}{c}\text { WIC } \\
\mathbf{N}=\mathbf{8 4} \\
\end{array}$ & $\begin{array}{c}\text { AEP } \\
\mathrm{N}=43 \\
\end{array}$ & p-value \\
\hline Weekly face-to-face group program, M (SD) & $5.2 \pm 1.8$ & $5.5 \pm 1.6$ & $5.0 \pm 2.0$ & .21 \\
\hline In need of childcare for face-to-face visits, $\%$ & 63.4 & 60.6 & 66.2 & .46 \\
\hline $\begin{array}{l}\text { Internet-based program with monthly } \\
\text { face-to-face visits, } M(\mathrm{SD})\end{array}$ & $4.4 \pm 2.3$ & $4.4 \pm 2.4$ & $4.3 \pm 2.2$ & .81 \\
\hline Weekly mail-based intervention, M (SD) & $4.8 \pm 1.8$ & $5.5 \pm 1.8$ & $4.0 \pm 1.8$ & .0001 \\
\hline Monthly home visits for mother, M (SD) & $4.4 \pm 2.1$ & $4.9 \pm 2.0$ & $3.8 \pm 2.1$ & .005 \\
\hline $\begin{array}{l}\text { Monthly home visits for mother \& family, M } \\
\text { (SD) }\end{array}$ & $4.0 \pm 2.1$ & $4.5 \pm 2.2$ & $3.5 \pm 2.0$ & .02 \\
\hline Weekly telephone calls, M (SD) & $3.6 \pm 2.3$ & $4.0 \pm 2.3$ & $3.2 \pm 2.3$ & .09 \\
\hline $\begin{array}{l}\text { Internet-based program } \\
\text { (no adjunct face to face visits), M (SD) }\end{array}$ & $3.5 \pm 2.3$ & $3.6 \pm 2.5$ & $3.4 \pm 2.1$ & .65 \\
\hline Weekly text message intervention, M (SD) & $2.4 \pm 3.7$ & $3.1 \pm 2.4$ & $1.7 \pm 1.3$ & .0001 \\
\hline
\end{tabular}


We also examined whether preferences differed based on time postpartum and other demographic variables and, in general, preferences were similar across these variables. However, some differences emerged. In both settings, women who were earlier postpartum ( $<12$ months) reported a stronger interest in interventions involving monthly home visits $(\mathrm{p}<$ $.03)$, weekly mailings $(\mathrm{p}<.02)$, and receiving text messages $(p<.01)$ than those later postpartum. Also, compared with normal weight women, women who were overweight/obese before pregnancy reported stronger preferences for an internet $(\mathrm{p}<.005)$, telephone $(\mathrm{p}<.001)$, and text messaging $(\mathrm{p}<.001)$ programs. Women who were normal weight before pregnancy $(\mathrm{p}<$ $.0001)$ or who had retained $>5 \mathrm{~kg}$ postpartum (p $=.02$ ) reported a greater preference for mailbased interventions $(\mathrm{p}<.0001)$. Finally, compared with English speakers, Spanish speakers had a greater interest in home visits ( $p$ $=.001)$, mailed based interventions $(\mathrm{p}=.002)$ and telephone interventions $(p=.01)$ than nonSpanish speakers. The degree of interest in treatment modalities did not differ based on breastfeeding status or age.

\section{Discussion}

Postpartum weight retention is a predictor of future obesity and weight gain (Gore et al., 2003). Finding ways to intervene to reduce high postpartum retention remains a research priority (Gore et al., 2003). Two settings where postpartum women often visit across the country, and where interventions could potentially be implemented, are WIC and community-based parenting programs for postpartum women. We examined the characteristics and treatment preferences of women in these two settings in Central California. We found that women in both settings had retained significant amounts of weight, but that postpartum weight retention was more pronounced among WIC women, independent of time postpartum. These results are consistent with prior research showing postpartum weight retention is problematic, and especially so among low- income women (L. Walker et al., 2004; Walker et al., 2005).
Given the greater prevalence of overweight and high postpartum weight retention among WIC participants, it is perhaps not surprising that more reported an interest in pursuing a weight loss program. Nonetheless, future research is needed to better understand why some overweight participants in both settings (approximately 20\% in each setting) and, more importantly, one-third to over half of women with high $(>5 \mathrm{~kg}$ ) postpartum weight retention (31.7\% of WIC and $55.1 \%$ of AEP) were not interested in pursuing a postpartum weight loss program. As high postpartum weight retention is a stronger predictor of future weight gain than pre-pregnancy obesity (Linne et al., 2004; Rooney \& Schauberger, 2002), future research is needed to better understand reasons for lack of interest in postpartum weight loss in this high risk group.

Populations in both settings reported high interest in weekly face-to-face weight loss groups but reported a need for childcare to make attendance feasible. Weight-loss programs that meet weekly are known to be most effective (D. Tate, Wing, \& Winett, 2001). However, researchers have questioned whether weekly group programs would be feasible for postpartum women who must find childcare and transportation to attend classes. These data suggest that women would be interested in weekly programs, but the costs of childcare would need to be considered.

Far fewer WIC than AEP participants reported using computers, email and internet, but most participants in both settings reported using the internet weekly or more and reported an interest in internet-based programs. An estimated two out of three adults in the US and $75 \%$ of adults under the age of 50 use the Internet, with $88 \%$ of users having access from home (Cooper \& Gallagher, 2004; Harwood \& Rainie, 2004; Pew Internet and American Life Project, 2004). A survey of 39,541 low-income postpartum women in Michigan, Illinois, or Indiana found that $75 \%$ of self-selected participants had access to the Internet from home, which was somewhat higher than the nearly $50 \%$ of low-income WIC participants in the current study (Bensley et al., 
2006). Given the exponential increases in rates of Internet access (128\% increase in 2008-2009), it has been estimated that Internet access will reach $>80 \%$ of the US population in coming years (Wagner, Bundorf, Singer, \& Baker, 2005). Numerous reports have concluded that the Internet is an important avenue for dissemination of health information and interventions for individuals of all income brackets (Eng, 2001; Eng \& Gustafson, 1999; Jimison, Adler, Coye, Mulley, \& Eng, 1999; Overhage, Evans, \& Marchibroda, 2005). Moreover, previous research has documented the benefits of internet-based behavioral weight loss programs (Tate, Jackvony, \& Wing, 2006; Tate, Wing, \& Winett, 2001). Future research should investigate the use of Internet-based programs to maximize program adherence and weight-loss outcomes in postpartum women.

Notably, although women in both settings reported an interest in monthly home visits, this modality was more popular among WIC and Spanish-speaking women than women in AEP and English-speakers. Home-based interventions have been modestly successful in promoting postpartum weight control in previous studies (Ostbye et al., 2009) and effective in reducing postpartum depression (Leis, Mendelson, Tandon, \& Perry, 2009). Home visits from nurses are also commonly offered as part of MediCal; thus, this modality may have been more familiar to the low-income WIC population. Nonetheless, despite its potential benefits, home visits may prove too costly in the current healthcare setting (Ostbye et al., 2009).

An interest in mail-based interventions was also reported, particularly among WIC women, Spanish speakers, women who were normal weight before pregnancy, and high weight retainers. Mail-based interventions have been shown in previous studies to reduce postpartum weight retention in higher income women (Leermakers et al., 1998). Future research is needed to investigate the effects of this modality in other populations.

This study is the first to compare the characteristics and preferences of women at two settings commonly cited as potential avenues for postpartum intervention (National Heart, Lung and Blood Institute, 2008). However, prospective assessments were not conducted, weight was based on self-report, gestational weight gain was not assessed, and women attending these venues were at different stages of the postpartum period. Moreover, patient interest in a program does not necessarily relate to program efficacy (Renjilian et al., 2001). Findings may not generalize to other postpartum populations or venues outside of Central California.

In sum, this study found that postpartum weight retention was prevalent in WIC and a community-based parenting program, and women across both settings reported a strong interest in postpartum weight loss intervention. Weekly face to face visits or less frequent face to face visits with adjunct internet-based treatment merit further investigation in randomized trials in both WIC and AEP settings. Other modalities, including mail and homebased interventions, should also be examined in diverse patient populations.

\section{References}

Artal, R., Catanzaro, R. B., Gavard, J. A., Mostello, D. J., \& Friganza, J. C. (2007). A lifestyle intervention of weight-gain restriction: Diet and exercise in obese women with gestational diabetes mellitus. Applied Physiology, Nutrition, and Metabolism, 32(3), 596-601.

Baker, J. L., Gamborg, M., Heitmann, B. L., Lissner, L., Sorensen, T. I., \& Rasmussen, K. M. (2008). Breastfeeding reduces postpartum weight retention. American Journal of Clinical Nutrition, 88(6), 1543-1551.

Bensley, R. J., Brusk, J. J., Anderson, J. V., Mercer, N., Rivas, J., \& Broadbent, L. N. (2006). wichealth.org: Impact of a stages of change-based Internet nutrition education program. Journal of Nutrition Education and Behavior, 38(4), 222-229. 
Phelan, S., Smith, K., Steele, J.M., Wilt, D., Ames, S., and McClure, L. / Californian Journal of Health Promotion 2010, Volume 8 ,

Issue 1, 22 - 31

Boney, C. M., Verma, A., Tucker, R., \& Vohr, B. R. (2005). Metabolic syndrome in childhood in association with birth weight, maternal obesity, and gestational diabetes mellitus. Pediatrics, 115(3), e290-296.

Bradley, L. P. (1995). Changing American birth through childbirth education. Patient Education and Counseling, 25(1), 75-82.

California WIC Association. (2008). California WIC Facts. Sacramento, CA: California WIC Association.

Caspe, M., \& Lopez, M. E. (Eds.). (2006). Lessons from family-strengthening interventions: Learning from evidence-based practice. MA: Cambridge.

Chow, J. C., Jaffee, K., \& Snowden, L. (2003). Racial/ethnic disparities in the use of mental health services in poverty areas. American Journal of Public Health, 93(5), 792-797.

Cole, N. (2001). The prevalence of overweight among WIC Children WIC-01-PCOM. Alexandria, VA: US Department of Agriculture, Food and Nutrition Service, Office of Analysis, Nutrition and Evaluation.

Cooper, K. B., \& Gallagher, M. D. (2004). A nation online: Entering the broadband age. Washington, DC: UD Department of Commerce.

Driul, L., Cacciaguerra, G., Citossi, A., Martina, M. D., Peressini, L., \& Marchesoni, D. (2008). Prepregnancy body mass index and adverse pregnancy outcomes. Archives of Gynecology and Obstetrics, 278(1), 23-26.

Eng, T. R. (Ed.). (2001). The eHealth landscape: A terrain map of emerging information and communication technologies in health and health care.: Robert Wood Johnson.

Eng, T. R., \& Gustafson, D. H. (Eds.). (1999). Wired for health and well-being: The emergence of interactive health communication. Washington, DC: US Department of Health and Human Services, US Government Printing Office.

Gore, S. A., Brown, D. M., \& West, D. S. (2003). The role of postpartum weight retention in obesity among women: A review of the evidence. Annals of Behavioral Medicine, 26(2), 149-159.

Greene, G. W., Smiciklas-Wright, H., Scholl, T. O., \& Karp, R. J. (1988). Postpartum weight change: How much of the weight gained in pregnancy will be lost after delivery? Obstetrics and Gynecology, 71, 701-707.

Groth, S. W., \& David, T. (2008). New mothers' views of weight and exercise. MCN The American Journal of Maternal Child Nursing, 33(6), 364-370.

Gunderson, E. P., Abrams, B., \& Selvin, S. (2001). Does the pattern of postpartum weight change differ according to pregravid body size? International Journal of Obesity and Related Metabolic Disorders, 25(6), 853-862.

Harwood, P., \& Rainie, L. (Eds.). (2004). People who use the Internet away from home and work (internet). Washington, DC: Pew Internet and American Life Project.

Institute of Medicine (1990). Nutrition During Pregnancy. Washington, D.C.: National Academy Press.

Jimison, H., Adler, L., Coye, M., Mulley, A., \& Eng, T. R. (1999). Health care providers and purchasers and evaluation of interactive health communication applications. American Journal of

Preventative Medicine, 16, 16-22.

Kac, G., Benicio, M. H., Velasquez-Melendez, G., \& Valente, J. G. (2004). Nine months postpartum weight retention predictors for Brazilian women. Public Health Nutrition, 7(5), 621-628.

Keppel, K. G., \& Taffel, S. M. (1993). Pregnancy-related weight gain and retention: Implications of the 1990 Institute of Medicine guidelines. American Journal of Public Health, 83, 1100-1103.

Kinnunen, T. I., Pasanen, M., Aittasalo, M., Fogelholm, M., Hilakivi-Clarke, L., Weiderpass, E., et al. (2007). Preventing excessive weight gain during pregnancy - A controlled trial in primary health care. European Journal of Clinical Nutrition, 61(7), 884-891.

Leermakers, E. A., Anglin, K., \& Wing, R. R. (1998). Reducing postpartum weight retention through a correspondence intervention. International Journal of Obesity, 22, 1103-1109. 
Leis, J. A., Mendelson, T., Tandon, S. D., \& Perry, D. F. (2009). A systematic review of home-based interventions to prevent and treat postpartum depression. Archives of Women's Mental Health, 12(1), 3-13.

Linne, Y., Dye, L., Barkeling, B., \& Rossner, S. (2004). Long-term weight development in women: A 15year follow-up of the effects of pregnancy. Obesity Research 12(7), 1166-1178.

Lovelady, C. A., Garner, K. E., Moreno, K. L., \& Williams, J. P. (2000). The effect of weight loss in overweight, lactating women on the growth of their infants. New England Journal of Medicine, $342(7), 449-453$.

McKeown, T., \& Record, R. G. (1957). The influence of weight and height on weight changes associated with pregnancy in women. The Journal of Endocrinology, 15(4), 423-429.

National Heart, Lung and Blood Institute. (2008). Targeted Approaches to Weight Control for Young Adults (U01) 2009, from http://grants.nih.gov/grants/guide/rfa-files/RFA-HL-08-007.html

Office of Disease Prevention and Health Promotion (Ed.). (2000). Healthy People 2010 (Internet). Washington, DC.

Ohlin, A., \& Rossner, S. (1990). Maternal body weight development after pregnancy. International Journal of Obesity. 14 (2), 159-173.

Olson, C. M., Strawderman, M. S., \& Dennison, B. A. (2008). Maternal weight gain during pregnancy and child weight at age 3 Years. Maternal and Child Health Journal. 13(6) 839-46.

Olson, C. M., Strawderman, M. S., \& Reed, R. G. (2004). Efficacy of an intervention to prevent excessive gestational weight gain. American Journal of Obstetrics and Gynecology, 191(2), 530-536.

Ostbye, T., Krause, K. M., Lovelady, C. A., Morey, M. C., Bastian, L. A., Peterson, B. L McBride, CM.(2009).Active mothers postpartum: a randomized controlled weight-loss intervention trial. American Journal of Preventative Medicine, 37(3), 173-180.

Overhage, J. M., Evans, L., \& Marchibroda, J. (2005). Communities' readiness for health information exchange: The National landscape in 2004. Journal of the American Medical Informatics Association, 12(2), 107-112.

Parker, J. D., \& Abrams, B. (1993). Differences in postpartum weight retention between black and white mothers. Obstetrics and Gynecology, 81, 768-774.

Pew Internet and American Life Project (Ed.). (2004). Older Americans and the Internet. Washington, DC: Pew Internet and American Life Project.

Polley, B. A., Wing, R. R., Meier, A., Sims, C., \& DeBranski, C. (1997). Preventing excessive weight gain during pregnancy in overweight and normal weight women. Annals of Behavioral Medicine, 19 (Suppl.), S071.

Renjilian, D. A., Perri, M. G., Nezu, A. M., McKelvey, W. F., Shermer, R. L., \& Anton, S. D. (2001). Individual versus group therapy for obesity: Effects of matching participants to their treatment preferences. Journal of Consulting and Clinical Psychology, 69(4), 717-721.

Rooney, B. L., \& Schauberger, C. W. (2002). Excess pregnancy weight gain and long-term obesity: One decade later. Obstetrics and Gynecology, 100(2), 245-252.

Samuels-Kalow, M. E., Funai, E. F., Buhimschi, C., Norwitz, E., Perrin, M., Calderon-Margalit, R, Harlap S.(2007). Prepregnancy body mass index, hypertensive disorders of pregnancy, and long-

term maternal mortality. American Journal of Obstetrics and Gynecology, 197(5), 490 e491-496.

Tate, D. F., Jackvony, E. H., \& Wing, R. R. (2006). A randomized trial comparing human e-mail counseling, computer-automated tailored counseling, and no counseling in an Internet weight loss program. Archives of Internal Medicine, 166(15), 1620-1625.

Tate, D. F., Wing, R. R., \& Winett, R. A. (2001). Using Internet technology to deliver a behavioral weight loss program. Journal of the American Medical Association, 285(9), 11721177.

Tate, D. F., Wing, R.R., Winett, R.A. (2001). Using internet technology to deliver a behavioral weight loss program. Journal of the American Medical Association, 285(No.9), 11721177. 
US Department of Agriculture (2008). WIC The special supplemental nutrition program for women, infants, and children. Washington, DC: Food and Nutrition Service.

Villamor, E., \& Cnattingius, S. (2006). Interpregnancy weight change and risk of adverse pregnancy outcomes: a population-based study. Lancet, 368(9542), 1164-1170.

Wagner, T. H., Bundorf, M. K., Singer, S. J., \& Baker, L. C. (2005). Free internet access, the digital divide, and health information. Medical Care, 43(4), 415-420.

Walker, L., Freeland-Graves, J. H., Milani, T., George, G., Hanss-Nuss, H., Kim, M, Stuifbergen A. (2004). Weight and behavioral and psychosocial factors among ethnically diverse, low-income women after childbirth: II. Trends and correlates. Women Health, 40(2), 19-34.

Walker, L. O. (2007). Managing excessive weight gain during pregnancy and the postpartum period. Journal of Obstetric Gynecologic and Neonatal Nursing, 36(5), 490-500.

Walker, L. O., Sterling, B. S., \& Timmerman, G. M. (2005). Retention of pregnancy-related weight in the early postpartum period: Implications for women's health services. Journal of Obstetric Gynecologic and Neonatal Nursing. 34(4), 418-427.

Walker, L. O., Timmerman, G. M., Sterling, B. S., Kim, M., \& Dickson, P. (2004). Keeping pregnancyrelated weight may result in long-term weight problems for women. Ethnicity and Disease, 14(1), 161-162.

Watkins, M. L., \& Botto, L. D. (2001). Maternal prepregnancy weight and congenital heart defects in offspring. Epidemiology, 12(4), 439-446.

\author{
Author Information \\ Suzanne Phelan, $\mathrm{PhD}^{*}$ \\ California Polytechnic State University \\ Department of Kinesiology \\ San Luis Obispo, CA 93407-0386 \\ Telephone: (805) 756 - 2087 \\ Facsimile: (805) 756 - 7273 \\ Email: sphelan@calpoly.edu \\ Katelyn Smith, BS \\ California Polytechnic State University \\ San Luis Obispo, CA \\ John-Mark Steele,BS \\ California Polytechnic State University \\ San Luis Obispo, CA \\ Dawn Wilt, RD, CLE \\ Women, Infant, Children's Nutritional Program (WIC) \\ San Luis Obispo County, CA, \\ Sally Ames, MA \\ San Luis Coastal Unified School District: \\ Parent Participation Program \\ San Luis Obispo, CA \\ Linda McClure, MS, RD \\ Women, Infant, Children's Nutritional Program \\ San Luis Obispo County, CA \\ * corresponding author
}

